\title{
THE SGIENTIFIC APPROACH TO ORTHOPAEDIC SURGERY
}

\author{
S. Alan S. Malkin \\ President of British Orthopaedic Association *
}

In choosing the subject of their presidential addresses some of my predecessors selected clinical matters in which they were specially interested, while others made observations of a more general character. Much of what I shall say to-day is the outcome of informal discussion with colleagues, young and old, and my purpose is to refer to certain aspects of our work which warrant more attention than they have received. Just as in the life of an individual it is necessary from time to time to reflect, and to consider whether objectives are being achieved, so in the life of a Society it is advisable occasionally, but not too often, to review the past, assess the present, and look into the future. This is particularly important to-day, not simply because this year our Association completes thirty years of life, but because we are living in difficult and changing times when it is more than ever necessary to see clearly where we are going.

I propose first to recall to your minds certain facts with which older members of the Association are familiar but which are less well known to younger members; and particularly to contrast the status of orthopaedic surgery at the time of the first World War with its status to-day. When war was declared in 1914 there were few orthopaedic surgeons in England. One-Sir Robert Jones-was outstanding both nationally and internationally. At that time there were few orthopaedic hospitals, but by the efforts of this great leader a number of special military surgical hospitals were established. Through his influence, American orthopaedic surgeons came over to England to assist in staffing these hospitals: it would have been quite impossible for Great Britain herself to supply all the surgeons necessary. It is interesting to remember that these hospitals were called "Special Military Surgical Hospitals" and not "Orthopaedic Hospitals." The word orthopaedic was not well received by some surgeons and it was thought better to avoid the use of it-an interesting commentary on the position at that time. Even by the standards of to-day you would have regarded these special hospitals as complete and fully equipped. There were, of course, differences. For example, no facilities were provided, as they were in the recent war, for strenuous exercises and games in the final stages of rehabilitation; nor were there special occupational therapy departments. Nevertheless, workshops were recognised as essential parts of the hospitals, and Sir Robert Jones was particularly keen that men should restore themselves to health and strength by their own efforts, and not rely on passive physiotherapy to do the job for them.

These hospitals prevented much deformity and disability, and later it was urged that the facilities which had been provided for the casualties of war should be made available to the cripples and potential cripples of peace. In 1919, Robert Jones and Gathorne Girdlestone published an article in the British Medical Journal which outlined a national plan for the prevention and treatment of crippling conditions, and for the training of cripples who could not easily take their place in the ordinary life of the community. This was one of the first experiments in Social Medicine, practised long before the birth of that subject as we know it to-day. The establishment of country orthopaedic hospitals was advocated, which with out-patient clinics and workshops would form complete units. The disinterested enthusiasm of many to whom this scheme appealed made it possible for such orthopaedic units to be established in Great Britain, ready to play their part in dealing with the casualties of the second World War. This time there was no doubt of the need for orthopaedic surgery and

* Presidential Address, delivered at the Annual Meeting of the British Orthopaedic Association in Belfast, October 1948.

vol. $31 \mathrm{~B}$, No. 1, FEBRUARY 1949 
orthopaedic hospitals. New hospitals had to be established for the reception of casualties, but those already in existence formed the nucleus of the national orthopaedic service. This in itself is an indication of the progress which has been made. There are many others, such as the fact that Chairs of Orthopaedic Surgery have been established in Oxford, Liverpool, and Manchester; that an orthopaedic surgeon has recently been appointed as professor of surgery at a London teaching hospital; that two leading members of our association are Members of the Council of the Royal College of Surgeons of England; and that, twice since its formation, the International Society of Orthopaedic Surgery has had for its president one of our members. It is fair to say that there are now few hospitals of size and standing in Great Britain without orthopaedic departments staffed by trained orthopaedic surgeons. Orthopaedics now, without question, embraces traumatic surgery; it co-operates with those who practise neurosurgery and plastic surgery; and it seeks within itself to develop such special work as the surgery of the hand. It has achieved this position not by narrowing but by broadening its outlook, and it insists that young orthopaedic surgeons should first gain a sound knowledge of, and a higher qualification in, general surgery.

From every point of view the Association can look back on the period since the first World War as one of great development and progress. But the real test of health and vigour is whether orthopaedic surgery attracts young men of ability and character who see in it the opportunity to lead useful and satisfying lives. Are they so attracted ? The succession of young men who have joined the ranks of our Association gives, not a weak, but a strongly affirmative answer to that question. It might be considered, therefore, that all is well, and that for progress to be maintained it is necessary only to continue on the lines already laid down. There are good reasons for believing that there need be no anxiety as to the security of the position of British orthopaedic surgery; but fortunately, as I believe, there are many weighty reasons for thinking just the reverse. If we are to continue to make that contribution to leadership in orthopaedic surgery, as practised throughout the world, which we could and should make, there is need for very clear thinking and for strenuous effort. I said that this was fortunate, for if a real effort on our part were not required we might fear that, added to our other troubles, there had fallen on Europe the worst of all evils-intellectual stagnation.

In our Constitution the object of the Association is stated to be "the advancement of the science and art of orthopaedic surgery." You will notice that it is not "the art and science," but " the science and art." It may be that the words were placed in that order for the sake of euphony, or because of custom, but it may also be that the order was chosen deliberately. Whatever the reason, I think it cannot be disputed that we have reversed the order and put art before science. Many of us have concentrated so much on technique and technical matters, which may, after all, be no more than temporary and short-lived, that we have neglected almost completely the scientific aspect of our work which could make a permanent contribution to knowledge. This does not mean that the standard of orthopaedic surgery in this country is low. I believe that any patient requiring orthopaedic treatment, wherever he lives in Great Britain, has within easy access the facilities which are necessary to give him sound and efficient treatment. But there has been greater interest in technical advance and new methods than in scientific progress, and there is no doubt that much of our work is empirical.

We know that many of the methods we employ depend on impressions of our results, sometimes indeed on our temperaments, and on changing fashions, rather than on clear and logical thought. Statistical analysis of our cases, and of our methods, is not always adequate; and sometimes, unwittingly on our part, we draw inferences which are quite incorrect and misleading. I fear that many of them would not bear the scrutiny of a trained statistician. We have all had the experience of visiting a hospital and being shown satisfactory results from one method of treatment, while at another hospital methods which were apparently quite different were claimed to be equally good. There are many instances: for example, the 
treatment of fractures of the spine with or without plaster fixation; the treatment of sciatica by rest or by operation; the functional as opposed to the anatomical treatment of fractures: and there are other, and perhaps better, examples. There must be some explanation for this diversity. It may be that we are unable to assess clearly what we have done. It may be that on occasion we have over-persuaded patients who will not let us down. It may be that we aim at producing the satisfied patient-an aim not to be belittled, but not the scientific test of success; or it may be that in diverse treatments there are common factors which themselves, though unrecognised, are the real causes of success. Such possibilities have this in common-they show a lack of the scientific outlook. I do not suggest that this is a British failing alone, although it may well be one to which we are prone because of our national instinct, and our tendency not to worry too much about theories but rather to aim at results. As " a nation of shopkeepers" it is perhaps not unnatural that we should be concerned with the delivery of goods. This is of course vitally important, and it does keep our feet firmly on the ground, but nevertheless it can be a source of weakness.

It may be contested that orthopaedic surgeons have taken full advantage of scientific developments and that there is no comparison between the results of treatment during the first and second World Wars. It may be said that many men who were injured in the second World War would never have returned to duty if they had been injured similarly in the first war. This is true; but it does not necessarily mean that orthopaedic surgery itself has become more scientific; it may be no more than that orthopaedic surgeons have utilised the results of the scientific work of others-work which produced penicillin, sulphonamides, and inert metals, which is a very different matter. I would not like it to be thought, and indeed it would be unjust to say, that really good scientific research has not been carried out; but what I do say is that many members of this Association have been concerned with practising orthopaedics as an art and not as a science. Few of us have that detached point of view which made Lambrinudi's observations of such value.

If we are to achieve the objects of this Association we must become more scientifically minded. We must give more attention to research in all its forms: clinical observation; experiment in man; and experiment in animals. Some years ago Wilfred Trotter pointed out that clinical observation, except in the hands of an occasional genius, had not been a very effective instrument by which to penetrate the fundamental secrets of health and disease, but that nevertheless it could be an important instrument for assessing the results of treatment if it was recognised, not as a spare time hobby to be indulged in when a paper was to be written, but as work which must be done constantly. It may be felt that, for such clinical observation, much time must be given ; and that in our over-worked state this is not possible. There is much truth in this. But the difficulty could be overcome if sufficient men of the right calibre-those who had reached the senior registrar or assistant surgeon status, having first gained some knowledge of statistics-were available to collect cases and assess treatment as part of their normal work. I do not think that many men, except occasionally and for a limited period, should devote their whole time to this type of research, but it should be one of their duties, at least in the early stage of their careers. The work of one man, dealing with a particular problem, should not necessarily be confined to one unit or centre; if it were not so confined the same judgment could be applied to comparable groups of cases treated by different methods. It would be possible in these circumstances for a man-if his mind were acute enough-by assessing the results of different types of treatment to find out what really was essential in each, thus at the same time advancing knowledge and simplifying treatment. He might also, by carefully assessing symptoms, deduce their real causes. Clinical observation, properly organised and conducted, could yield a rich harvest.

Experiment in man has some value in orthopaedic surgery but the application is limited. It may be used from time to time to prove that deductions made from clinical observations are correct. As a rule, however, such experiments as are possible will deal more with methods

VOL. $31 \mathrm{~B}$, NO. 1, FEBRUARY 1949 
of treatment and technique than with assessment of the causes of disease. As an instance I would quote from the diary of Dr John Knyveton (1763-1809). " June 3, 1777. M. Sigault, a surgeon of Paris, has made a great noise and stir by dividing the pubic symphysis in a case of child-birth, in order to free the child's head by dividing the bony ring of the pelvis. The French government have awarded him a pension, and a medal has been struck in his honour: but I do not like the sound of the business at all, and have but lately returned from Mr John Hunter, with whom I discussed the matter. . . . Nevertheless, in order that the exact degree of utility of this new operation may be accurately assessed, Mr Hunter will perform a series of operations on the symphysis in company with his brother William: and Mr Osborne is to collect all information, examining the cases published and the results of the operations of the brothers Hunter, so as to prove by facts and experiments the use or otherwise of this new treatment." This is surely the plan-experts to perform the operation, and independent observers to assess the results.

Apart from clinical observation, the method to which we must look for most advance in orthopaedic surgery is animal experimentation and laboratory research. But here is a great difficulty: few of us are trained research workers, and moreover it is hard to combine research with routine clinical duties. It is probably true that research is best done by the young. Indeed it is said by some of considerable experience that the best and most original research work is done before the age of thirty. This does not mean that no research is done after that age but very often, though carried out later, it was conceived in youth. Lister and Hunter began their experiments when they were still young. Isaac Newton made discoveries at the age of twenty-four, and it is interesting to remember that his great work was begun in the disturbed years of the Plague, and the Fire of London, in 1665 and 1666, when there was probably far less security of life than there is to-day. Referring to himself when he was at this age, Isaac Newton said: "I was in the prime of my age for inventions, and minded mathematics and philosophy more than at any time since." It may be, as Francis Bacon observed: "the invention of young men is more lively than that of the old, and imagination streams in their minds, as it were, more divinely." The concensus of opinion seems to be that youth is the best time for research. The point for us is that the man who specialises in orthopaedic surgery, and who reaches the status of an assistant orthopaedic surgeon by about the age of thirty, will have passed the time when he could have done his best work. Moreover, research demands much knowledge of the basic sciences; it must be carried out in institutions; and it must be correlated with work in other fields. How can the dilemma be overcome? First by close co-operation between orthopaedic surgeons and physiologists. Just as in some clinics the anatomist is a member of the orthopaedic team, so the physiologist should be invited to join us and find answers to some problems which can be solved only in the laboratory. The physiologist could do fundamental research; he would be the link with other sciences; and our part would be to put problems before him, to discuss possible solutions, and to assist in technical details as required. May I remind you that twenty-seven years elapsed before recognition of the enormous clinical value of sulphanilamide, discovered in Vienna in 1908 by a scientist, Gelmo; and that it was very many years after Sir Alexander Fleming discovered penicillin in his London laboratory that clinical applications were first made. The links between medicine and science must be forged much more strongly.

My second proposal is that every man while training in orthopaedic surgery should, during one year, spend time in the research laboratory. This need not necessarily be full-time work; nor do I think that every man is equally fitted for research. But I do believe that, whether fitted or not, such experience would stimulate his scientific outlook. As Goethe said: "He who with inadequate talent devotes himself to music will never indeed become a Master, but he will learn to know and value a masterly production."

I must turn for a moment to the National Health Services Act, which is having such far-reaching effects on our profession. Section 16 states: "1) Without prejudice to the general 
powers and duties conferred or imposed on the Minister under the Ministry of Health Act, 1919, and the duties imposed on the Committee of the Privy Council for Medical Research under the said Act, the Minister may conduct or assist by grants or otherwise any person to conduct research into any matters relating to the causation, prevention, diagnosis or treatment of illness or mental defectiveness. 2) The Board of Governors of a teaching hospital and a Regional Hospital Board and a Hospital Management Committee, shall have power to conduct research into any of the matters aforesaid." The Government, therefore, directly through its hospital boards and management committees, has assumed the duty of providing research facilities, and it is for us to see that these facilities are developed fully. The executive of this Association has felt that it could assist in co-ordinating research by forming a special research committee. To this committee anyone can appeal for assistance, particularly when work is to be done at more than one centre. The committee will serve in promoting liaison and it may also initiate special studies.

Important research is being carried out in many parts of the world. Investigations have been undertaken in America on the mineral and protein content of bone in relation to function and form. Work in the University of Chicago on the spontaneous recovery of muscles after incomplete denervation may have important applications in the treatment of infantile paralysis. In Stockholm the properties of articular cartilage in the normal subject, and in various pathological states, has been studied. There have been important studies in this country, and at this meeting you have heard of the research of young members of our Association into the regeneration of human muscle after ischaemic necrosis, and the causes of premature epiphyseal fusion in osteoporosis. But how much more there is to be done. Consider the problem of scoliosis. Is so-called idiopathic scoliosis always, or sometimes, due to unrecognised poliomyelitis? Can its progress be prevented in the early stages? What is the best method of treatment? And again, why does the upper femoral epiphysis sometimes slip in adolescence? We have concentrated on treatment, but the real problem is that of prevention, and there is need for both physiological and biochemical studies. Think of the problems of sciatica. What is the physiological, anatomical, and pathological background of degenerations and displacements of disc lesions? Can they be prevented? Many other examples will come to the mind of every member of the Association.

In conclusion, I would remind you that in concentrating on the scientific aspect of our work we should do no more than return to the ideals of the founder of British scientific surgery-John Hunter. In delivering a Hunterian oration, Sir James Paget said: " Hunter's greatest work was in physiology . . . He brought the scientific method into the study of practice and he welded scientific knowledge with the lessons of experience. . . . Either science or art can do many things; even a one-handed man is far from helpless; but two hands are better; they should work together in harmony with mutual help; for the best work can be done only when the power and skill of science and art are combined, as with one thought and one design. It was thus that Hunter wrought in surgery."

Let us make this our aim. Let us combine the science and art of orthopaedic surgery as with one thought and one design. 